\title{
Value of digital mammography in predicting lymphovascular invasion of breast cancer
}

\author{
Zhuangsheng Liu ${ }^{1 \dagger}$, Ruqiong $\mathrm{Li}^{1 \dagger}$, Keming Liang ${ }^{1}$, Junhao Chen ${ }^{1}$, Xiangmeng Chen ${ }^{1}$, Xiaoping $\mathrm{Li}^{2}$, Ronggang Li ${ }^{3}$, \\ Xin Zhang ${ }^{4}$, Lilei Yi ${ }^{5}$ and Wansheng Long ${ }^{1 *}$
}

\begin{abstract}
Background: Lymphovascular invasion (LVI) has never been revealed by preoperative scans. It is necessary to use digital mammography in predicting LVI in patients with breast cancer preoperatively.

Methods: Overall 122 cases of invasive ductal carcinoma diagnosed between May 2017 and September 2018 were enrolled and assigned into the LVI positive group $(n=42)$ and the LVI negative group $(n=80)$. Independent t-test and $\times 2$ test were performed.

Results: Difference in Ki-67 between the two groups was statistically significant $(P=0.012)$. Differences in interstitial edema $(P=0.013)$ and skin thickening $(P=0.000)$ were statistically significant between the two groups. Multiple factor analysis showed that there were three independent risk factors for LVI: interstitial edema (odds ratio [OR] = 12.610; $95 \%$ confidence interval [CI]: 1.061-149.922; $P=0.045)$, blurring of subcutaneous fat $(\mathrm{OR}=0.081 ; 95 \% \mathrm{Cl}$ : $0.012-0.645 ; P=0.017)$ and skin thickening $(\mathrm{OR}=9.041 ; 95 \% \mathrm{Cl}: 2.553-32.022 ; P=0.001)$.

Conclusions: Interstitial edema, blurring of subcutaneous fat, and skin thickening are independent risk factors for LVI. The specificity of LVI prediction is as high as $98.8 \%$ when the three are used together.
\end{abstract}

Keywords: Lymphovascular invasion, Breast cancer, Digital mammography

\section{Background}

Breast cancer metastasizes through lymphatic and blood vessels, which makes the patients susceptible to distant metastasis, postoperative recurrence and even death. Lymphovascular invasion (LVI) has never been revealed by preoperative scans. Diagnostic histopathology is needed to reveal LVI of cancer cells. Preoperative identification of LVI can help to predict the prognosis of patients with breast cancer, especially those with axillary

\footnotetext{
* Correspondence: jmlws2@163.com

'Zhuangsheng Liu and Ruqiong Li contributed equally to this work. 'Department of Radiology, Jiangmen Central Hospital, Affiliated Jiangmen Hospital of Sun Yat-Sen University, No. 23 Haibang Street, Jiangmen 529000, Guangdong, China

Full list of author information is available at the end of the article
}

node-negative breast cancer, and to develop adjuvant treatment plans in clinical settings $[1,2]$.

Digital mammography is one of the important imaging tools for breast cancer screening and diagnosis. There have been many reports on prediction of axillary lymph node metastasis [3-5] and on digital mammography screening [6-9]. However, there has been no report on predicting LVI of breast cancer based on imaging patterns of digital mammography, except a little literature in which MRI findings were used for prediction [2, 10-12].

It is necessary to use digital mammography, a more readily available imaging tool, in preoperative prediction of LVI in patients with breast cancer, and to evaluate the predictive specificity of the imaging findings and certain biomarkers detected by immunohistochemistry so as to

(c) The Author(s). 2020 Open Access This article is licensed under a Creative Commons Attribution 4.0 International License, which permits use, sharing, adaptation, distribution and reproduction in any medium or format, as long as you give appropriate credit to the original author(s) and the source, provide a link to the Creative Commons licence, and indicate if changes were made. The images or other third party material in this article are included in the article's Creative Commons licence, unless indicated otherwise in a credit line to the material. If material is not included in the article's Creative Commons licence and your intended use is not permitted by statutory regulation or exceeds the permitted use, you will need to obtain permission directly from the copyright holder. To view a copy of this licence, visit http://creativecommons.org/licenses/by/4.0/ The Creative Commons Public Domain Dedication waiver (http://creativecommons.org/publicdomain/zero/1.0/) applies to the data made available in this article, unless otherwise stated in a credit line to the data. 
better foresee disease progression and develop targeted treatment plans.

\section{Methods \\ Clinical data}

This single-center retrospective study enrolled 122 cases of invasive ductal carcinoma diagnosed between May 2017 and September 2018. Since the data were obtained from a picture archiving and communication system, patients' informed consent was not required for this study. The inclusion criteria were: (1) modified radical mastectomy or breast-conserving surgery + axillary lymph node dissection; (2) diagnosis of invasive breast cancer confirmed by routine histopathological and immunohistochemical examinations; (3) no previous history of breast tumors or primary tumors in other locations; and (4) LVI status confirmed by immunohistochemistry. Patients were excluded if they had obscured lesions revealed by digital mammograms, were breastfeeding, had underwent lumbar puncture or radiotherapy prior to diagnosis, and had incomplete clinical data.

Mammographic lesions were confirmed either by core needle biopsies or by surgical pathology. All the patients underwent digital mammography preoperatively. All of them were female and aged between 26 and 77 with a median age of 45 . They were assigned into the LVI positive group $(n=42)$ and the LVI negative group $(n=80)$.

\section{Digital mammography}

GE (Senographe DS) and IMS (GIOTTO IMAGE) systems were used. Four standard body positions were imaged under automatic exposure conditions, and they were the right craniocaudal (RCC) view, left craniocaudal (LCC) view, right mediolateral oblique (RMLO) view and left mediolateral oblique (LMLO) view. When lesions were found in the axillary tail of Spence or near the cleavage, amplified imaging in these locations was done to reveal the lesions fully. The flat-panel detector of internal and external obliques was parallel to the pectoralis major muscle. According to the patients' body shape, the projecting angle ranged from $40^{\circ}$ to $65^{\circ}$ and was usually $60^{\circ}$. The glands were fully unfolded, and the skin folds below the breasts and upper abdomen were within the mammographic field.

\section{Image analysis}

The imaging characteristics of breast cancer lesions were described according to the 5 th edition of ACR BI-RADS ${ }^{\circ}$ Atlas published in 2013 [13]. The lesions were classified into four types: mass, calcification, architectural distortion, and asymmetry. There could be one or more masses. The masses could be round, lobulated, and irregular. Clear and sharp edges meant well circumscribed margins, clear and sharp edges obscured by glands meant obscured margins, while obscured and spiculated edges meant indistinct margins. Amorphous and fine polymorphic calcifications were included, while typically benign calcifications were excluded. Architectural distortion referred to abnormal deformation of breasts without any mass clearly revealed by imaging. History of trauma and surgery must be ruled out under this circumstance. Focal asymmetry was seen in two images, but lacks the outward border or a mass. There were only few cases of architectural distortion and focal asymmetry (both $n<$ 5). Those cases were excluded to avoid inaccurate statistical results. And the lesion type was classified as mass and calcification only.

Associated features included nipple discharge, interstitial edema, blurring of subcutaneous fat layer, skin thickening, and axillary adenopathy (lymph nodes measuring $>1 \mathrm{~cm}$ in the long axis diameter with absence of hilus. If enlarged lymph nodes are new, they need to be clinically combined and further examined). Due to its absence in the LVI negative group $(n=0)$, nipple discharge was not included as a variable. Thickening of the skin means that the affected breast has localized or diffuse thickening of the skin greater than $2 \mathrm{~mm}$ in thickness. Interstitial edema and subcutaneous fat layer blurring are caused by the filling and dilation of lymphatic vessels and blood vessels in the breast, while the performance of the whole breast including subcutaneous fat layer is blurring, and multiple cord shadows are seen.

\section{Pathology}

Surgically resected breast cancer specimens were fixed in $10 \%$ formaldehyde for $24 \mathrm{~h}$, then were dehydrated and embedded in paraffin wax. Sections were prepared. Standard HE stain and streptavidin-peroxidase-biotin (SP) immunohistochemical method were performed. DAB detection systems were used. A score of 3 and more indicated Her-2 overexpression. Positive FISH result of Her-2 gene amplification also indicated overexpression when the score was 2 and more. Ki67 proliferative index (PI) of $<10 \%$ indicated low expression level, while that of $>30 \%$ indicated high expression level. Ki67 PI of 10 to $30 \%$ indicated intermediate expression level [14].

The gold standard of this study was that LVI was defined as the intravenous tumor emboli and lymphatic tumor emboli detected by immunohistochemistry. These two kinds of tumor emboli were clinically referred to as intralymphovascular tumor emboli due to the difficulty of distinguishing them with pathological sections. The specimens were read by a senior pathologist who had been working on breast cancer for 21 years.

\section{Statistical analysis}

The data were analyzed using SPSS Version 19.0. The quantitative data were expressed as means \pm SDs. The 
Table 1 Comparison of patient characteristics according to lymphovascular invasion

\begin{tabular}{|c|c|c|c|c|c|c|c|c|c|}
\hline & \\
\hline Characteristics & Total & $\begin{array}{l}\mathrm{LVI}=0 \\
\text { (Negative) }\end{array}$ & $\begin{array}{l}\mathrm{LVI}=1 \\
\text { (Positive) }\end{array}$ & $P$ & Characteristics & Total & $\begin{array}{l}\mathrm{LV}=0 \\
\text { (Negative) }\end{array}$ & $\begin{array}{l}\mathrm{LVI}=1 \\
\text { (Positive) }\end{array}$ & $P$ \\
\hline Age & 122 & $49.99(10.17)$ & $48.93(9.34)$ & 0.566 & $>2 \mathrm{~cm}$ & 43 & $24(55.81)$ & 19(44.19) & \\
\hline History of giving birth & 122 & 80 & 42 & 0.488 & Single/multiple & 122 & 80 & 42 & 0.746 \\
\hline No & 5 & $4(80.00)$ & $1(20.00)$ & & Single & 95 & $63(66.32)$ & $32(33.68)$ & \\
\hline Yes & 117 & $76(64.96)$ & $41(35.04)$ & & Multiple & 27 & $17(62.96)$ & 10(37.04) & \\
\hline History of abortion & 122 & 80 & 42 & 0.560 & Lesions & 122 & 80 & 42 & 0.8855 \\
\hline No & 86 & $55(63.95)$ & $31(36.05)$ & & Mass & 65 & $43(66.15)$ & $22(33.85)$ & \\
\hline Yes & 36 & $25(69.44)$ & $11(30.56)$ & & Mass/calcification & 57 & $37(64.91)$ & 20(35.09) & \\
\hline nipple discharge & 122 & 80 & 42 & & Location & 122 & 80 & 42 & 0.879 \\
\hline No & 120 & $80(66.67)$ & $40(33.33)$ & & Outer upper & 73 & $49(67.12)$ & $24(32.88)$ & \\
\hline Yes & 2 & $0(0.00)$ & $2(100.00)$ & & Outer lower & 5 & $4(80.00)$ & $1(20.00)$ & \\
\hline $\mathrm{CA} 153^{\mathrm{a}}$ & 121 & 79 & 42 & 0.514 & Lower inner & 15 & $10(66.67)$ & $5(33.33)$ & \\
\hline Negative & 117 & $77(65.81)$ & 40(34.19) & & Upper inner & 15 & $9(60.00)$ & $6(40.00)$ & \\
\hline Positive & 4 & $2(50.00)$ & $2(50.00)$ & & Central area & 14 & $8(57.14)$ & $6(42.86)$ & \\
\hline History of related illness & 122 & 80 & 42 & 0.488 & Mass shape & 122 & 80 & 42 & 0.160 \\
\hline No & 117 & $76(64.96)$ & $41(35.04)$ & & Lobulated & 16 & $8(50.00)$ & $8(50.00)$ & \\
\hline Yes & 5 & $4(80.00)$ & $1(20.00)$ & & Irregular & 106 & $72(67.92)$ & $34(32.08)$ & \\
\hline ER & 122 & 80 & 42 & 0.062 & Mass Margin & 122 & 80 & 42 & 0.088 \\
\hline Negative & 39 & $21(53.85)$ & $18(46.15)$ & & Smooth & 6 & $2(33.33)$ & $4(66.67)$ & \\
\hline Positive & 83 & 59(71.08) & $24(28.92)$ & & Rough & 116 & $78(67.24)$ & $38(32.76)$ & \\
\hline PR & 122 & 80 & 42 & 0.0591 & Boundary & 122 & 80 & 42 & 0.714 \\
\hline Negative & 47 & $26(55.32)$ & $21(44.68)$ & & Clear & 69 & $47(68.12)$ & $22(31.88)$ & \\
\hline Positive & 75 & $54(72.00)$ & $21(28.00)$ & & Obscure & 27 & 16(59.26) & $11(40.74)$ & \\
\hline HER-2 & 122 & 80 & 42 & 0.994 & Shield & 26 & $17(65.38)$ & $9(34.62)$ & \\
\hline Negative & 32 & $21(65.63)$ & $11(34.38)$ & & Calcification $^{a}$ & 56 & 36 & 20 & 0.279 \\
\hline Positive & 90 & $59(65.56)$ & $31(34.44)$ & & Vague and amorphous & 25 & 18(72.00) & $7(28.00)$ & \\
\hline $\mathrm{E}-\mathrm{cad}^{\mathrm{a}}$ & 87 & 56 & 31 & 0.100 & Fine polymorphous & 31 & 18(58.06) & 13(41.94) & \\
\hline Negative & 6 & $2(33.33)$ & $4(66.67)$ & & Interstitial edema & 122 & 80 & 42 & 0.013 \\
\hline Positive & 81 & $54(66.67)$ & $27(33.33)$ & & No & 110 & $76(69.09)$ & $34(30.91)$ & \\
\hline Ki-67 & 122 & 80 & 42 & 0.012 & Yes & 12 & $4(33.33)$ & $8(66.67)$ & \\
\hline Low & 27 & $20(74.07)$ & $7(25.93)$ & & Subcutaneous fat & 122 & 80 & 42 & 0.697 \\
\hline Moderate & 36 & $29(80.56)$ & $7(19.44)$ & & Clear & 101 & $67(66.34)$ & $34(33.66)$ & \\
\hline High & 59 & $31(52.54)$ & $28(47.46)$ & & Muddy & 21 & 13(61.90) & $8(38.10)$ & \\
\hline P53 & 122 & 80 & 42 & 0.126 & Thicken Skin & 122 & 80 & 42 & $<0.001$ \\
\hline Negative & 40 & $30(75.00)$ & $10(25.00)$ & & No & 86 & $65(75.58)$ & $21(24.42)$ & \\
\hline Positive & 82 & $50(60.98)$ & $32(39.02)$ & & Yes & 36 & $15(41.67)$ & $21(58.33)$ & \\
\hline Amount of fibroglandular & 122 & 80 & 42 & 0.431 & Nipple retraction & 122 & 80 & 42 & 0.073 \\
\hline 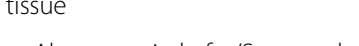 & & & & & No & 98 & 68(69.39) & $30(30.61)$ & \\
\hline $\begin{array}{l}\text { Almost entirely fat/Scattered } \\
\text { fibroglandular tissue }\end{array}$ & 49 & 33(67.35) & 16(32.65) & & Yes & 24 & $12(50.00)$ & $12(50.00)$ & \\
\hline $\begin{array}{l}\text { Heterogeneous } \\
\text { fibroglandular tissue }\end{array}$ & 54 & $37(68.52)$ & $17(31.48)$ & & $\begin{array}{l}\text { Axillary lymph node } \\
\text { enlargement }\end{array}$ & 122 & 80 & 42 & 0.166 \\
\hline Extreme fibroglandular tissue & 19 & $10(52.63)$ & $9(47.37)$ & & No & 77 & $54(70.13)$ & $23(29.87)$ & \\
\hline Size & 122 & 80 & 42 & 0.094 & Yes & 45 & $26(57.78)$ & $19(42.22)$ & \\
\hline
\end{tabular}

Table 1 Comparison of patient characteristics according to lymphovascular invasion (Continued)

${ }^{a}$ Missing value exists

LVI Lymphovascular invasion 
independent $\mathrm{t}$-test was done for intergroup comparisons. The count data were expressed as frequencies or rates, and the $\mathrm{X}^{2}$ test or Fisher's method was performed. $P<$ 0.05 indicated statistically significant difference. The count data whose values were 0 were excluded from statistical analysis and listed only in table(s).

\section{Results}

\section{General data and biomarkers}

Table 1 presents the data about childbearing history, miscarriage history, history of other breast diseases, nipple discharge, CA153, age, ER, PR, HER-2, E-CAD, P53, and Ki-67. Difference in Ki-67 between the LVI positive group and the LVI negative group was statistically significant $(P=0.012)$, while no statistically significant differences were observed in the other factors mentioned.

\section{Digital mammography findings}

Details are shown in Table 1. Differences in interstitial edema $(P=0.013$, Figs. 1 and 2$)$ and skin thickening $(P=0.000$, Figs. 1 and 2$)$ between the two groups were statistically significant. No statistically significant intergroup differences were seen in other imaging features, such as fibroglandular tissue density $(P=0.431)$, radiological diameter $(P=0.094)$, mass number $(P=0.746)$, lesion number $(P=0.8855)$, location $(P=0.879)$, mass shape $(P=0.160)$, mass margin $(P=0.088)$, boundary

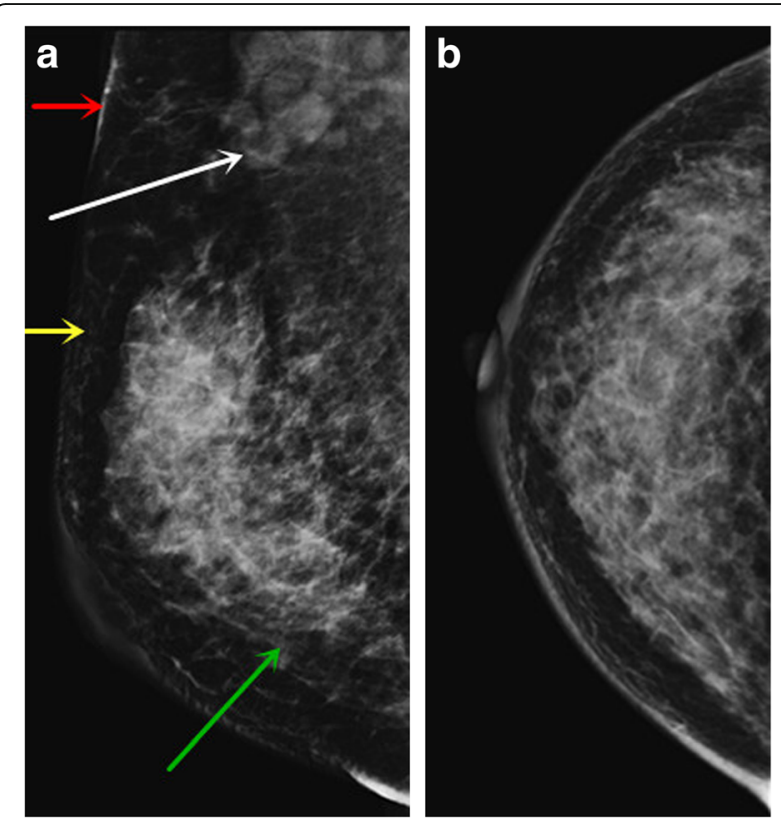

Fig. 1 Female, LVI positive. The MLO position (a) and CC position (b) of digital mammography showed an irregular upper mass with blurred boundaries in the upper outer quadrant of the right breast. Interstitial edema (green arrow), blurring of subcutaneous fat layer (yellow arrow), skin thickening (red arrow), and axillary adenopathy (white arrow) were observed in the right breast

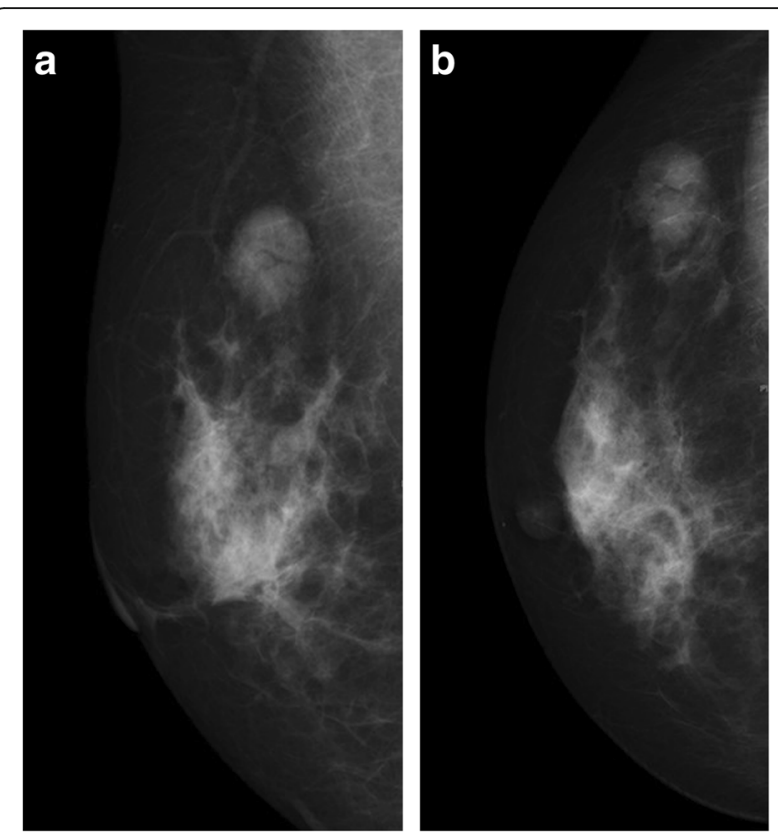

Fig. 2 Female, LVI negative. The MLO position (a) and CC position (b) of the digital mammography showed a circular mass with smooth edges and clear boundaries in the upper outer quadrant of the right breast. No accompanying patterns (such as interstitial edema or skin thickening) were seen

$(P=0.714)$, calcification $(P=0.279)$, subcutaneous fat $(P=0.697)$, nipple retraction $(P=0.073)$ and axillary adenopathy $(P=0.166)$.

Risk factor analysis results are shown in Table 2 . Multiple factor analysis showed that there are three independent risk factors for LVI: interstitial edema (odds ratio $[\mathrm{OR}]=12.610$; 95\% confidence interval $[\mathrm{CI}]: 1.061-$ 149.922; $P=0.045)$, subcutaneous fat $(\mathrm{OR}=0.081 ; 95 \%$ CI: $0.012-0.645 ; P=0.017)$ and skin thickening $(\mathrm{OR}=$ 9.041; 95\% CI: $2.553-32.022 ; P=0.001$ ).

Table 3 shows the sensitivity, specificity, accuracy, positive predictive value and negative predictive value of the three independent risk factors in LVI prediction. The specificity of LVI prediction was as high as $98.8 \%$ when they were applied together.

\section{Discussion}

LVI or intralymphovascular tumor emboli is closely related to the adverse outcome of many malignant tumors [15-17]. As a risk factor for recurrent breast cancer following modified radical mastectomy, lymphovascular tumor emboli, especially lymphatic tumor emboli, has been included in the St Gallen consensus for breast cancer [18]. Karlsson et al. [19] reported that the failure rate of chemotherapy was higher in breast cancer patients with LVI than those without. Shen et al. [20] found that lymphovascular tumor emboli promoted recurrence and distant metastasis of local tumors. Therefore, presence 
Table 2 Univariate and multivariate analysis

\begin{tabular}{|c|c|c|c|c|}
\hline \multirow[t]{2}{*}{ Factors } & \multicolumn{2}{|l|}{ Univariate analysis } & \multicolumn{2}{|l|}{ Multivariate analysis } \\
\hline & OR $(95 \% \mathrm{Cl})$ & P & OR $(95 \% \mathrm{Cl})$ & $P$ \\
\hline Interstitial edema & $4.471(1.260,15.864)$ & 0.020 & $12.610(1.061,149.922)$ & 0.045 \\
\hline Subcutaneous fat & $1.213(0.458,3.207)$ & 0.698 & $0.081(0.012,0.645)$ & 0.017 \\
\hline Thicken Skin & $4.333(1.899,9.891)$ & 0.000 & $9.041(2.553,32.022)$ & 0.001 \\
\hline ER & $0.475(0.216,1.044)$ & 0.064 & $1.595(0.252,10.084)$ & 0.62 \\
\hline$P R$ & $0.481(0.224,1.034)$ & 0.061 & $0.508(0.085,3.035)$ & 0.458 \\
\hline HER-2 & $1.003(0.429,2.345)$ & 0.994 & $1.436(0.462,4.466)$ & 0.532 \\
\hline \multicolumn{5}{|l|}{ Ki-67 } \\
\hline Moderate & $0.690(0.209,2.273)$ & 0.541 & $0.382(0.094,1.551)$ & 0.178 \\
\hline High & $2.581(0.948,7.022)$ & 0.063 & $1.298(0.350,4.809)$ & 0.696 \\
\hline P53 & $1.920(0.827,4.457)$ & 0.129 & $2.115(0.739,6.050)$ & 0.163 \\
\hline \multicolumn{5}{|l|}{ Amount of fibroglandular tissue } \\
\hline Heterogeneous fibroglandular tissue & $0.948(0.414,2.179)$ & 0.899 & $1.439(0.491,4.215)$ & 0.507 \\
\hline Extreme fibroglandular tissue & $1.856(0.630,5.469)$ & 0.262 & $3.773(0.707,20.154)$ & 0.12 \\
\hline Size & $1.928(0.890,4176)$ & 0.096 & $0.921(0.294,2.891)$ & 0.889 \\
\hline Nipple retraction & $2.267(0.914,5.621)$ & 0.077 & $1.299(0.281,5.991)$ & 0.738 \\
\hline Single/multiple & $1.158(0.476,2.819)$ & 0.746 & $1.183(0.336,4.165)$ & 0.793 \\
\hline Lesions & $1.057(0.500,2.233)$ & 0.885 & $0.712(0.256,1.979)$ & 0.514 \\
\hline Mass shape & $0.472(0.163,1.365)$ & 0.166 & $0.624(0.128,3.047)$ & 0.56 \\
\hline Margin & $0.224(0.043,1.389)$ & 0.112 & $0.424(0.032,5.630)$ & 0.516 \\
\hline \multicolumn{5}{|l|}{ Boundary } \\
\hline Obscure & $1.469(0.586,3.684)$ & 0.413 & $1.483(0.439,5.007)$ & 0.526 \\
\hline Shield & $1.131(0.436,2.935)$ & 0.800 & $0.997(0.246,4.043)$ & 0.997 \\
\hline Axillary lymph node enlargement & $1.716(0.797,3.694)$ & 0.168 & $0.909(0.295,2.805)$ & 0.868 \\
\hline E-cad & $0.250(0.043,1.452)$ & 0.122 & & \\
\hline \multicolumn{5}{|l|}{ Location } \\
\hline Outer lower & $0.510(0.054,4.819)$ & 0.557 & & \\
\hline Lower inner & $1.021(0.314,3.320)$ & 0.973 & & \\
\hline Upper inner & $1.361(0.434,4.267)$ & 0.597 & & \\
\hline Central area & $1.531(0.477,4.913)$ & 0.474 & & \\
\hline Calcification & $1.857(0.601,5.734)$ & 0.166 & & \\
\hline Family history & $1.927(0.117,31.602)$ & 0.646 & & \\
\hline History of giving birth & $2.158(0.233,19.947)$ & 0.498 & & \\
\hline History of abortion & $0.781(0.339,1.799)$ & 0.561 & & \\
\hline CA15-3 & $1.925(0.261,14.179)$ & 0.52 & & \\
\hline History of related illness & $0.463(0.050,4.284)$ & 0.498 & & \\
\hline
\end{tabular}

Table 3 Diagnostic performance

\begin{tabular}{llllll}
\hline Methods & Sensitivity & Specificity & Accuracy & PPV & NPV \\
\hline Interstitial edema & $19.0(8 / 42)$ & $95.0(76 / 80)$ & $68.9(84 / 122)$ & $66.7(8 / 12)$ & $69.1(76 / 110)$ \\
Thicken Skin & $50.0(21 / 42)$ & $81.3(65 / 80)$ & $70.5(86 / 122)$ & $58.3(21 / 36)$ & $75.6(65 / 86)$ \\
Subcutaneous fat & $19.0(8 / 42)$ & $83.8(67 / 80)$ & $61.2(75 / 122)$ & $38.1(8 / 21)$ & $66.3(67 / 101)$ \\
All factors & $14.3(6 / 42)$ & $98.8(79 / 80)$ & $69.7(85 / 122)$ & $65.7(6 / 7)$ & $68.7(79 / 115)$ \\
\hline
\end{tabular}


of lymphovascular tumor emboli is a reliable indicator for distant metastasis of breast cancer and an important factor influencing overall survival. This article aimed to predict the risk of LVI of breast cancer using various digital mammography features.

There are no statistically significant differences in age, childbearing history, miscarriage history, family history and other medical history between the LVI positive group and the LVI negative group. Nulliparity, miscarriage, and family history of breast cancer are not associated with increase of LVI occurrence.

CA153 is a tumor marker first discovered in breast cancer cells. Its specificity is relatively high in diagnosis of breast cancer. Diagnostic sensitivity of CA153 increases from 66 to $80 \%$ as breast cancer advances [21]. However, in this study, there are only 4 cases of positive CA153 (3.3\%). Though there are no statistical significant differences in ER, PR, Her-2, E-cad, and P53 between the two groups, the LVI positive group have more cases of high Ki-67 expression level (>30\%) than the LVI negative group and the difference is statistically significant $(P=0.012)$. Some literature have confirmed that Ki-67 is associated with tumor differentiation, LVI, metastasis, and recurrence [22-24].

There are no statistically significant differences between the two groups in mammographic density, location, number, radiological diameter, shape, margin, boundary, calcification. Therefore, the above factors cannot be used to predict LVI. However, intergroup differences in interstitial edema and skin thickening are statistically significant $(P=0.013$ and 0.000 , respectively). In addition, multivariate analysis demonstrates that interstitial edema, blurring of subcutaneous fat, and skin thickening are independent risk factors for LVI $(P=0.045,0.017$ and 0.001 , respectively). In clinical work-up, physicians should be highly alerted about LVI occurrence when digital mammography reveals the above three phenomena. Even if lymph node metastasis is negative in sentinel lymph node and axillary lymph node biopsies, there is possibility that breast cancer cells has infiltrated surrounding vessels but not metastasized upwards to the axillary lymph nodes yet. Besides, modification of postoperative adjuvant therapy should be considered to reduce risk of recurrence and distant metastasis, and thus to prolong survival.

We believed that the axillary lymph nodes shown on digital mammography could be used to predict LVI. However, there are no differences between the two groups in axillary lymph nodes $(P=0.166)$. One possible explanation might be that digital mammography failed to reveal axillary lymph nodes. In addition, an enlarged $(>1 \mathrm{~cm})$ or complete lymph node does not always suggest metastasis. There is possibility of reactive hyperplasia.

\section{Conclusions}

There is statistically significant difference in Ki-67 between the LVI positive group and the LVI negative group. Interstitial edema, blurring of subcutaneous fat and skin thickening are independent risk factors for LVI $(P=0.045,0.017$, and 0.001 , respectively). When the three imaging features are applied together, the specificity of LVI prediction is as high as $98.8 \%$.

\section{Abbreviations \\ LVI: Lymphovascular invasion; DM: Digital mammography; RCC: Right craniocaudal; LCC: Left craniocaudal; RMLO: Right mediolateral oblique; LMLO: Left mediolateral oblique}

\section{Acknowledgements}

We would like to thank the study teams from Jiangmen Central Hospital and Foshan Hospital of Traditional Chinese Medicine for their continuous support.

\section{Author's contributions}

ZSL and RQL participated in study design, evaluated the results and wrote the first and revised manuscripts. KML, JHC and XMC participated in study design and supplied contrast media. XPL RGL and XZ analyzed the images and revised manuscripts. LLY and WSL participated in study design and redesigned data analysis. All authors read and approved the final manuscript.

\section{Funding}

This work was supported by the National Natural Science Foundation of China (Grant No. 81802918) and the Science and Technology Planning Project of Jiangmen (Grant No. 2017A4016; Grant No. 2015068). These are earmarked funds for cancer research. The funding bodies have no role in study design, data collection, data analysis, data interpretation, or manuscript preparation

\section{Availability of data and materials}

Data to replicate findings are in the Figures and Tables of the main paper. Due to patient privacy protection, any additional materials of the study are only available upon individual request directed to the corresponding author.

Ethics approval and consent to participate

The study was approved by the Jiangmen Central Hospital and the requirement for signed informed consent was waived.

\section{Consent for publication}

Not applicable.

\section{Competing interests}

The authors declare that they have no competing interests.

\section{Author details}

'Department of Radiology, Jiangmen Central Hospital, Affiliated Jiangmen Hospital of Sun Yat-Sen University, No. 23 Haibang Street, Jiangmen 529000, Guangdong, China. ${ }^{2}$ Department of Gastrointestinal Surgery, Jiangmen Central Hospital, Affiliated Jiangmen Hospital of Sun Yat-Sen University, Jiangmen, Guangdong, China. ${ }^{3}$ Department of Pathology, Jiangmen Central Hospital, Affiliated Jiangmen Hospital of Sun Yat-Sen University, Jiangmen, Guangdong, China. ${ }^{4}$ Department of Clinical Experimental Center, Jiangmen Central Hospital, Affiliated Jiangmen Hospital of Sun Yat-Sen University, Jiangmen, Guangdong, China. ${ }^{5}$ Department of Radiology, Foshan Hospital of Traditional Chinese Medicine, Foshan, Guangdong, China.

Received: 14 November 2019 Accepted: 3 March 2020

Published online: 03 April 2020

\section{References}

1. Rezaianzadeh A, Talei A, Rajaeefard A, et al. Lymphovascular invasion as an independent prognostic factor in lymph node negative invasive breast cancer. Asian Pac J Cancer Prev. 2012;13(11):5767-72.

2. Oy F, BI G, Xy H, et al. A nomogram for individual prediction of lymphovascular invasion in primary breast cancer. Eur J Radiol. 2019;110:30-8. 
3. Yang JB, Wang $T$, Yang $L F$, et al. Preoperative prediction of axillary lymph node metastasis in breast cancer using mammography-based Radiomics method. Sci Rep. 2019;9:4429.

4. Cen DZ, Xu L, Zhang SW, et al. BI-RADS 3-5 microcalcifications: prediction of lymph node metastasis of breast cancer. Oncotarget. 2017;8(18):30190-8.

5. Karahallı Ö, Acar T, Atahan MK, et al. Clinical and pathological factors affecting the sentinel lymph node metastasis in patients with breast cancer. Indian J Surg. 2017;79(5):418-22.

6. Hubbard RA, Zhu W, Horblyuk R, et al. Diagnostic imaging and biopsy pathways following abnormal screen-film and digital screening mammography. Breast Cancer Res Treat. 2013;138(3):879-87.

7. Lee $\mathrm{Cl}$, Cevik M, Alagoz O, et al. Comparative effectiveness of combined digital mammography and Tomosynthesis screening for women with dense breasts. Radiology. 2015;274(3):772-80.

8. Jewett PI, Gangnon RE, Elkin E, et al. Geographic access to mammography facilities and frequency of mammography screening. Ann Epidemiol. 2018; 28(2):65-71.

9. O'Donoghue C, Eklund M, Elissa M, et al. Aggregate cost of mammography screening in the United States: comparison of current practice and advocated guidelines. Ann Intern Med. 2014;160(3):145.

10. Hyejin C, Hye JK, So ML, et al. Preoperative MRI features associated with Lymphovascular invasion in node-negative invasive breast cancer: a propensity-matched analysis. J Magn Reson Imaging. 2017;46(4):1037-44.

11. Mori N, Mugikura S, Takasawa C, et al. Peritumoral apparent diffusion coefficients for prediction of lymphovascular invasion in clinically nodenegative invasive breast cancer. Eur Radiol. 2016;26:331-9.

12. Liu ZS, Bao F, Li CL, et al. Preoperative prediction of Lymphovascular invasion in invasive breast cancer with dynamic contrast-enhanced-MRI-based Radiomics. J Magn Reson Imaging. 2019:50(3):847 [Epub ahead of print].

13. American College of Radiology (ACR). Breast imaging reporting and data system (BI-RADS). 5th ed. Reston: Ameirican College of Radiology; 2013. p. 133.

14. Barbashina V, Adriana D, Corben MD. Mucinous micropapillary carcinoma of the breast:an aggressive counterpart to conventional pure mucinous tumors. Hum Pathol. 2013:44:1577-85.

15. Liang JW, Gao P, Wang ZN, et al. The integration of macroscopic tumor invasionof adjacent organs into TNM staging system for colorectal cancer. PLoS One. 2012;7(12):52269.

16. Lai JH, Zhou YJ, Bin D, et al. Clinical significance of detecting lymphatic and blood vessel invasion in stage II colon cancer using markers D2-40 and CD34 in combination. Asian Pac J Cancer Prev. 2014;15(3):1363-7.

17. Matloff E. Cancer principles and practice of oncology: handbook of clinical cancer genetics. J Am Med Assoc. 1990;248(15):1904-5.

18. Mignatiadis MB, Sotiriou C. St Gallen international expert consensus on the primary therapy of early breast cancer: an invaluable tool for physicians, and scientists. Ann Oncl. 2012;26(8):1519-20.

19. Karlsson P, Cole BF, Price KN, et al. The role of the number of uninvolved lymph nodes in predicting locoregional recurrence in breast cancer. J Clin Oncol. 2007;25(15):2019-26.

20. Shen $\mathrm{S}$, Zhong $\mathrm{S}$, Lu H, et al. A meta-analysis of lymphatic vessel invasion correlated with pathologic factors in invasive breast cancer. J Cancer Ther. 2015;6:315-21.

21. Choi JW, Moon BI, Lee JW, et al. Use of CA15-3 for screening breast cancer: an antibody-lectin sandwich assay for detecting glycosylation of CA15-3 in sera. Oncol Rep. 2018:40(1):145-54.

22. Menon SS, Guruvayoorappan C, Sakthivel KM, et al. Ki-67 protein as a tumour proliferation marker. Clin Chim Acta. 2019:491:39-45.

23. Zhang H, Sui X, Zhou S, et al. About "correlation of conventional ultrasound characteristics of breast tumors with axillary lymph node metastasis and ki67 expression in patients with breast cancer". J Ultrasound Med. 2019;38(7): 1833. https://doi.org/10.1002/jum.14930 [Epub ahead of print].

24. Peng $J H$, Zhang $X$, Song $J L$, et al. Neoadjuvant chemotherapy reduces the expression rates of ER, PR, HER2, Ki67, and P53 of invasive ductal carcinoma. Medicine (Baltimore). 2019;98(2):e13554.

\section{Publisher's Note}

Springer Nature remains neutral with regard to jurisdictional claims in published maps and institutional affiliations.

\section{Ready to submit your research? Choose BMC and benefit from:}

- fast, convenient online submission

- thorough peer review by experienced researchers in your field

- rapid publication on acceptance

- support for research data, including large and complex data types

- gold Open Access which fosters wider collaboration and increased citations

- maximum visibility for your research: over $100 \mathrm{M}$ website views per year

At $\mathrm{BMC}$, research is always in progress.

Learn more biomedcentral.com/submissions 